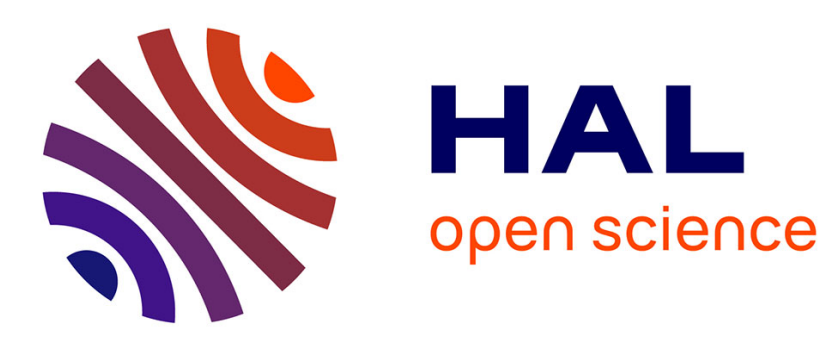

\title{
Dry Particle High-Impact Coating of Biopowders: Coating Strength
}

\author{
S. Oetles, Olivier Lecoq, John A. Dodds
}

\section{To cite this version:}

S. Oetles, Olivier Lecoq, John A. Dodds. Dry Particle High-Impact Coating of Biopowders: Coating Strength. Particulate Science and Technology, 2009, 27 (4), pp.352-361. 10.1080/02726350902993987 . hal-01680762

\section{HAL Id: hal-01680762 https://hal.science/hal-01680762}

Submitted on 6 Nov 2019

HAL is a multi-disciplinary open access archive for the deposit and dissemination of scientific research documents, whether they are published or not. The documents may come from teaching and research institutions in France or abroad, or from public or private research centers.
L'archive ouverte pluridisciplinaire HAL, est destinée au dépôt et à la diffusion de documents scientifiques de niveau recherche, publiés ou non, émanant des établissements d'enseignement et de recherche français ou étrangers, des laboratoires publics ou privés. 


\title{
Dry Particle High-Impact Coating of Biopowders: Coating Strength
}

\author{
S. ÖTLES, O. LECOQ, AND J. A. DODDS \\ Ecole des Mines d'Albi-Carmaux, RAPSODEE Research Center, \\ Albi, France
}

\begin{abstract}
The aim of this study is to develop a fundamental knowledge on dry coating, to understand the coating strength of different bio-couples with a theoretical and experimental approach and how the dry coating is affected by the size of host particle and choice of dry particle coating equipment. For this purpose, we examine the feasibility of dry coating of two different particle size distributions of Cellets particles with talc using a Nara Hybridizer NHS-0, a 1 L Cyclomix, and a Turbula blender. Special care is required to choose suitable operating conditions in order to achieve surface modification without breakage phenomena. An experimental methodology based on a commercial granulometer is used to study the coating strength of the composites and allows us to study the influence of particle size. The conclusion is that the smaller the guest-to-host size ratio, the stronger the coating. This result is in agreement with the estimation of particle adhesion with the help of a van der Waals approach. The influence of the coating equipment is also studied. The Hybridizer leads with the chosen operating conditions to the stronger coating.
\end{abstract}

Keywords adhesion, bio-powders, dry coating, Nara hybridizer, strength, van der Waals

\section{Introduction}

Over the past years, particle coating technology has grown in importance in both industrial applications and academic research. Powder coating is a method that focuses on modifying or improving some specific properties of powders that the natural product does not offer. Examples are flowability, dispersibility, solubility, wettability (hydrophilic/hydrophobic properties), electrostatic, electric, magnetic, optical, color, flavor, taste, particle shape/sphericity, sinterability, and solid phase reactivity in both dry and wet conditions (Pfeffer et al. 2001; Yang et al. 2005).

In dry particle coating processes, small (occasionally submicron-size) guest particles are coated onto larger (10 to 100 times) host particles in order to create value-added composite particulate materials Figure 1. The guest particles are brought into close contact with the host particles through the application of mechanical forces. Thus, either a discrete or continuous coating of guest particles can be achieved depending on the equipment, the powder characteristics, and the

This work has been accomplished within the BioPowders project, a RTN Marie Curie action financed by the 6th European Framework Programme.

Address correspondence to O. Lecoq, Ecole des Mines d'Albi-Carmaux, RAPSODEE Research Center, Albi 81013, France. E-mail: lecoq@enstimac.fr 


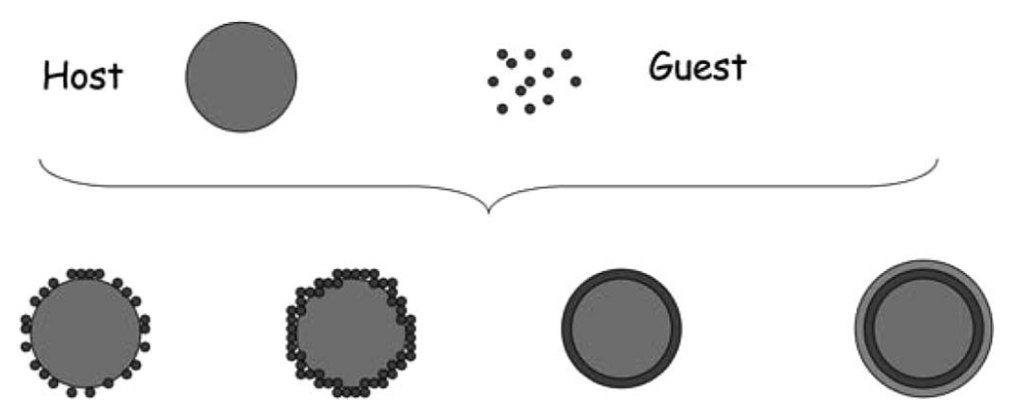

Figure 1. Monolayer discrete, continuous (porous), continuous (film), and multilayer dry coating results.

process conditions including processing time and weight fraction of guest to host particles (Ramlakhan et al. 2000; Mujumdar et al. 2007).

The coating mechanisms are complex but from a general point of view they are linked to the interparticle forces such as van der Waals force, moisture bonding, electrostatic force, solid bridging, and mechanical interlocking. However, it is still difficult to quantify them correctly and to correlate them with the process. In this work we want to understand the influence of the host particle size and the coating equipment on the mechanical coating strength of the obtained composite particles.

\section{Experimental Methodology}

\section{Materials}

Cellets 90 and Cellets 200 particles from Pharmatrans Sanaq AG used as two different host components were coated with talc particles from Luzenac S.A. Table 1. These Cellets are pellets made of microcrystalline cellulose. As inert carriers, they are mainly used for controlled release formulations and for drug delivery. In this study two different particle sizes of Cellets have been used because the particles have a regular spherical shape, smooth surface, and very high mechanical strength that allows us to compare the effect of host particle size on coating strength of the powder couple. Talc is used in food and pharmaceutical industry as an effective anticaking agent and lubricant.

\section{Methods}

In this study a Hybridizer (NHS-0, Nara Machinery, Japan), a Cyclomix (capacity 1 L, Hosokawa Micron B.V., Japan) and a Turbula blender (WAB A.G., Switzerland), shown in Figure 2, were used as the dry particle coating equipment.

The Hybridizer is a batch-operated device (maximum $50 \mathrm{~g}$ ) with an active volume of about half a liter. It has three main parts: a high-speed rotor with six

Table 1. Properties of the particles

\begin{tabular}{lcccc}
\hline Materials & $d[1.0](\mu \mathrm{m})$ & $d[4.3](\mu \mathrm{m})$ & $\rho_{\text {apparent }}(\mathrm{g} / \mathrm{mL})$ & $\rho_{\text {solid }}(\mathrm{g} / \mathrm{mL})$ \\
\hline Cellets 90 & 74 & 100 & 0.80 & 1.52 \\
Cellets 200 & 217 & 305 & 0.80 & 1.52 \\
Talc & 0.3 & 14 & 0.25 & 2.80 \\
\hline
\end{tabular}



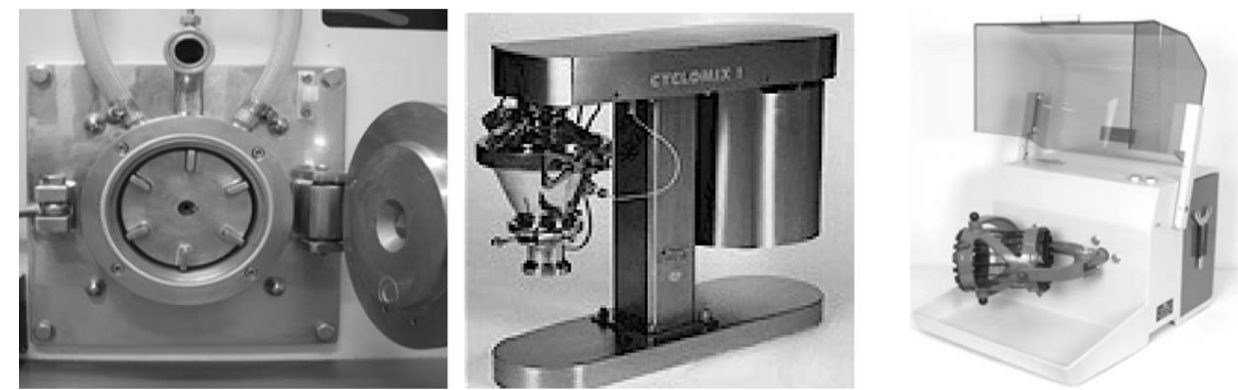

Figure 2. Nara Hybridizer NHS-0 (left), Cyclomix 1 L (center), Turbula blender (right).

blades, a stator, and a powder recirculation tube. The stator is surrounded by a circulating cooling or heating fluid jacket so that thermo-sensitive materials can be processed. Inside the hybridizer the host and the guest particles are subjected to high impaction and dispersion due to high rotating speed of the rotor. The particles undergo many collisions with each other, with the blades of the rotor and with the walls of the stator. The powders are repeatedly impacted, which breaks up agglomerates of the fine guest particles and attaches them to the surfaces of the large host particles with the formation of a discrete or continuous layer. The Hybridizer can be operated at different rotational speeds (up to $16000 \mathrm{rpm}$ ) and operation times (from $30 \mathrm{~s}$ up to $10 \mathrm{~min}$ ) (Singh et al. 2001).

The Cyclomix is another type of high force mixer for dry particle coating. The mixing vessel is conical shaped and has a central impeller (with four sets of blades) that rotates at a speed up to $3000 \mathrm{rpm}$. The rotation creates centrifugal forces and pushes the product to the vessel wall. The conical shape of the vessel causes an upward movement of the product, which is reintroduced to the center when it reaches the top of the mixer, creating a circulation loop ( $\mathrm{Ng}$ et al. 2007). The Cyclomix is also equipped with a cooling/heating jacket.

The Turbula is another type of mixer that allows mixing of powders by rotational movements of the chamber. It can generate rotational speeds from 22 to $96 \mathrm{rpm}$.

In this study $30 \mathrm{~g}$ batches (corresponding to optimum filling conditions, i.e., good mixing and recirculation) of host Cellets 90 and Cellets 200 particles with guest talc particles were processed with the Hybridizer under the same rotational speed of $4000 \mathrm{rpm}$ (chosen to avoid fragmentation), with a processing time of $6 \mathrm{~min}$ (knowing that in such devices, it is admitted that the coating is achieved in $2-3 \mathrm{~min}$ and does not change with further processing time). For the Cyclomix, $500 \mathrm{~mL}$ batches (considered classically as the minimum volume for good mixing and recirculation) of host and guest particles were used. The rotational speed was chosen as $1600 \mathrm{rpm}$ (to avoid fragmentation) for $6 \mathrm{~min}$ processing time (same as for the Hybridizer). For the experiments with the Turbula, the host particles, Cellets 90 and Cellets 200, were pre-manipulated by the Hybridizer at $4000 \mathrm{rpm}$ and then they were mixed with talc in the Turbula ( $30 \mathrm{~g}$ batches) at $96 \mathrm{rpm}$ for $6 \mathrm{~min}$. In this study the host particles Cellets 90 were coated with $10 \%$ talc, and Cellets 200 were coated with $5 \%$ talc. This corresponds for the two couples to $20 \%$ of the maximum coverage of the host particles by the guest particles, according to the following model. We consider here a 2-D coverage model with nondeformable monosized particles. The relation for 
monolayer coverage of a host sphere with guest spheres is given by the general Equation (1). The mass of guest particles/mass of host particles is:

$$
\frac{m_{\text {guest }}}{m_{\text {host }}}=\frac{1}{1+\frac{1}{4 C d^{\prime} \rho^{\prime}\left(1+d^{\prime}\right)^{2}}}
$$

with $d^{\prime}=d_{\text {guest }} / d_{\text {host }}$ and $\rho^{\prime}=\rho_{\text {guest }} / \rho_{\text {host }}$ and $C$ the packing fraction or coverage, i.e., the ratio of the covered surface to the total surface. If we consider hexagonal compact packing, the coverage $C$ is at its maximum value, i.e., $\pi / 2 \sqrt{3}=0.906$. Other coverage models can be possible (Hinrichsen et al. 1990). In this reference situation, this means the total covered surface is not $100 \%$ but only $91 \%$. For the first couple (respectively the second), the hexagonal monolayer is achieved with around $50 \%$ (respectively $25 \%$ ) of guest-to-host mass ratio. We have chosen to work with only one-fifth of that quantity to be in a "similar coverage situation" for the two couples.

In addition, Cellets 90 and Cellets 200 particles were also mixed with talc particles by a simple manual mixing method. These are referred to as the "basic mixing" samples and were prepared by simply mixing the Cellets and talc together with a spatula for $6 \mathrm{~min}$. These samples were compared with those prepared with the Hybridizer, Cyclomix, and Turbula.

A Malvern Mastersizer with the Sirocco dry powder feeding system was used to evaluate the strength of the coating on the host particles. The range of particle size measurement of the Mastersizer is from 0.02 to 2,000 microns. In this apparatus powder de-agglomeration is controlled by adjusting the dispersing air pressure (from 0.1 to 4.0 bar) in a coaxial venturi feeding system followed by a right-angle tube. The falling sample is first accelerated in the vertical part after the feeding funnel. Then, the particles reach the right-angle tube: the sudden change of direction creates an impacting zone, de-agglomerating the sample. If the powder is too fragile, breakage may occur.

In this study we determined at which dispersing air pressure the guest particles start to be liberated from the host particles according to a previously developed methodology in our laboratory (Vilela et al. 2005). This liberation pressure, even though arbitrary, is an interesting tool to compare different coatings.

\section{Results and Discussion}

\section{Preliminary Study}

As a preliminary study, samples of Cellets 90 and Cellets 200 were processed alone for $6 \mathrm{~min}$ in the Hybridizer at different speeds of rotation: 4,000, 5,600, and $9,600 \mathrm{rpm}$. The particle size of the final Cellets particles were determined with the Mastersizer and expressed as the $d[4.3]$ or volume mean diameter. In addition, the yield of the Hybridizer was determined, that is, the percentage of material removed from the device at the end of an experiment with respect to the amount put in at the start. The results are shown in Figure 3.

As expected, the yield never reaches $100 \%$, because of particles adhering on the walls of the equipment. This is amplified when the velocity is increased. A possible reason would be that agitation tends to create fines (de-agglomeration or attrition) that are more likely to stick to the surfaces. In the time and velocity ranges investigated, this phenomenon does not change the $d[4.3]$, which is a volumeaveraged diameter and hence not influenced by a small increase of fine particles. 


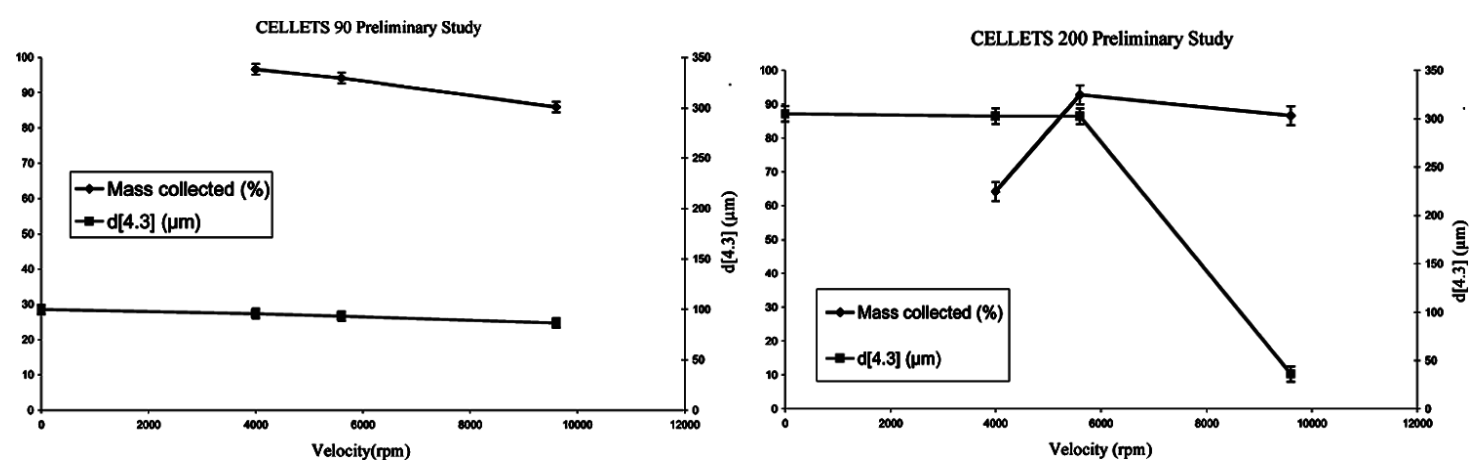

Figure 3. Yield and size for the two hybridized Cellets.

For Cellets 200, the situation is different. At 4,000 to $5,600 \mathrm{rpm}$, the yield is increased because the increase of agitation helps the purge of the particles out of the apparatus. After 5,600 rpm, breakage occurs: the yield and the size decrease. The $4,000 \mathrm{rpm}$ velocity is chosen as we want to avoid breakage and study only the coating phenomena.

It can be seen that the powder produced at low speeds of rotation has an initial particle size $d[4.3]$ of about $100 \mu \mathrm{m}$ for Cellets 90 and $305 \mu \mathrm{m}$ for Cellets 200 , but the mean particle size is reduced with higher speeds of rotation greater than $5,600 \mathrm{rpm}$. This would indicate particle breakage at these high speeds of rotation. To be able to understand the effect of host particle size on the coating strength we need to avoid particle breakage or at least to minimize it. For that reason $4,000 \mathrm{rpm}$ rotational speed was chosen for the Hybridizer. The same concept was applied to the experiments using the Cyclomix and the Turbula. Rotational speeds were chosen in order to avoid breakage of the host particles.

\section{Effect of Dry Coating Equipment on Coating Strength}

The methodology used to evaluate the coating strength is based on particle size analysis by the Malvern Mastersizer in dry feed mode. Ideally, increasing the dispersing air pressure causes liberation of the guest particles from the surface of the host particles. This threshold liberation pressure is detected by following the number fraction particle size distribution (nPSD) in parallel with the volume fraction particle size distribution vPSD (Vilela et al. 2005; Ouabbas et al. 2007). The nPSD is derived from the vPSD by assuming spherical particles. By definition the number fraction $x_{N i}$ is linked to the volume fraction $x_{V i}$ according to:

$$
x_{N i}=\frac{x_{V i} d_{i}^{3}}{\sum x_{V i} d_{i}^{3}}
$$

The methodology is based on the simultaneous analysis of the volume and number particle size distributions. It is important to recall that qualitatively speaking, the vPSD is masking the "fine particles" information (when existing) and is adapted to visualize the information of the "larger particles." The nPSD is masking the "large particles" information (when existing) and is adapted to visualize the "finer particles" that could not be detected in the vPSD.

Figures 4 and 5 give the evolution of the number and volume distributions with dispersing pressures $(0.5$ to 4.0 bar $)$ showing three main populations of particles. 


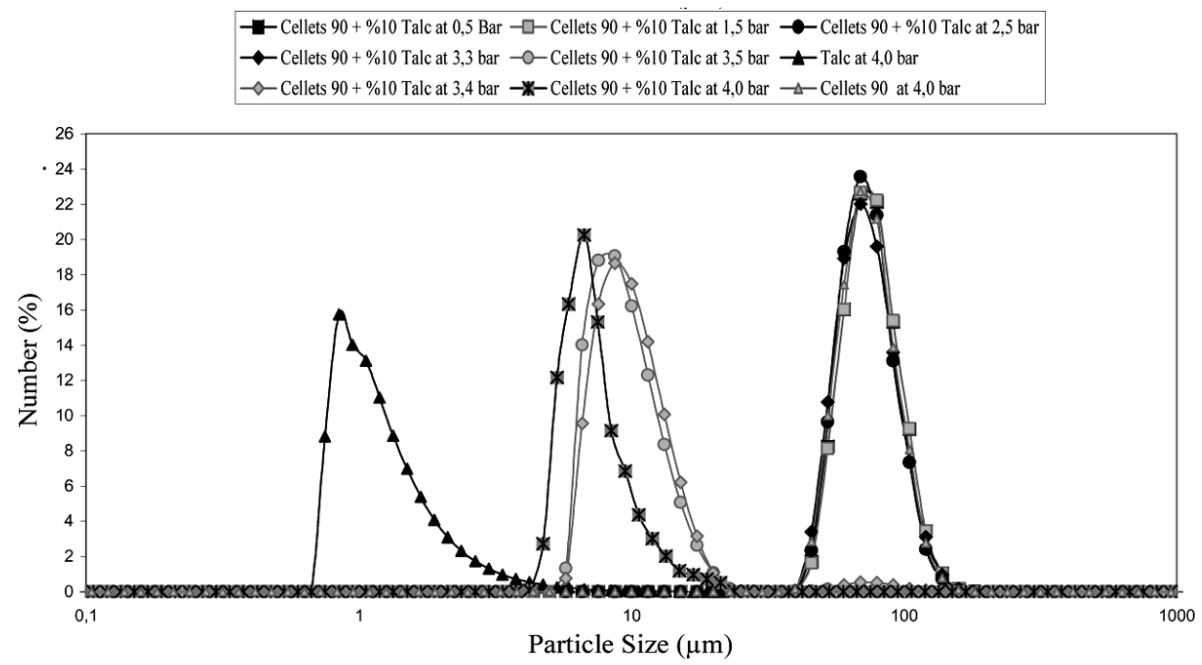

(a)

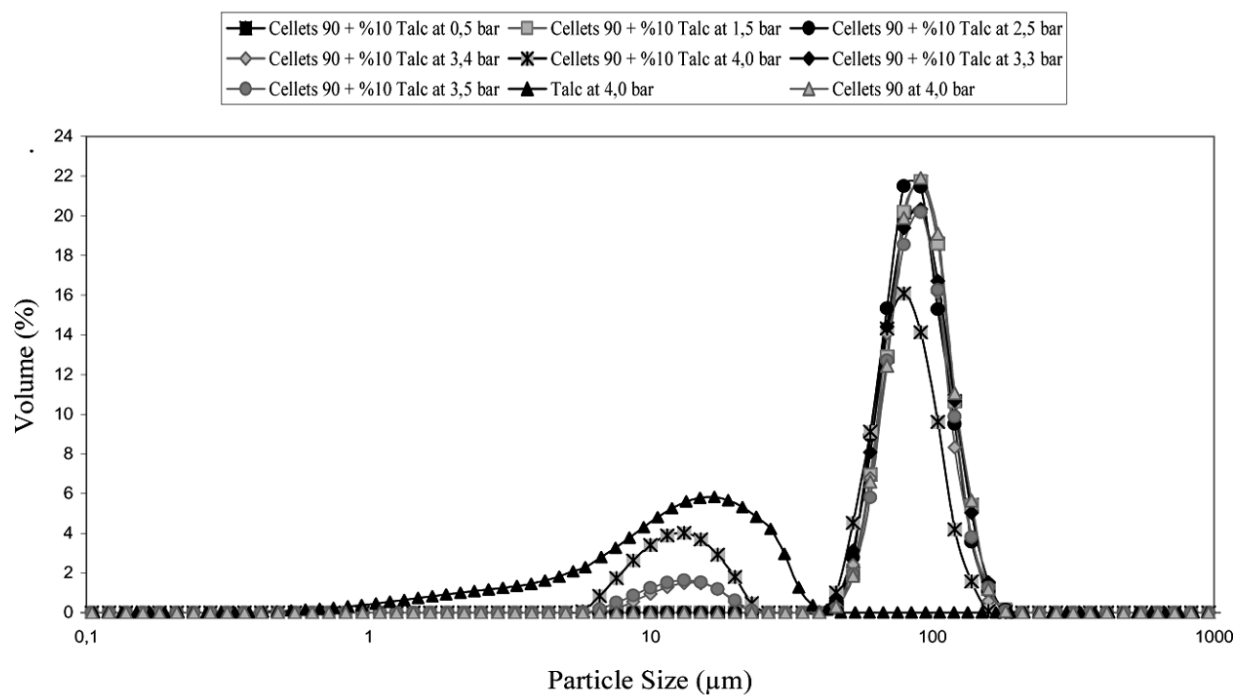

(b)

Figure 4. (a) Evolution of number size distributions with dispersing pressures (Cellets $90+$ $10 \%$ talc in the Hybridizer) and (b) Evolution of volume size distributions with dispersing pressures (Cellets $90+10 \%$ talc in the Hybridizer).

In Figure 4, the first population at about $100 \mu \mathrm{m}$ is maintained until 3.4 bar pressure. After 3.4 bar pressure, the particles start to detach from each other and the nPSD moves towards the distribution of talc powder. This indicates that for the Cellets 90 particles coated with $10 \%$ talc by the Hybridizer, the coating is maintained until 3.4 bar pressure.

It is important to notice that in Figure 4 (also in Figure 5) the nPSDs after detachment are different from the initial composite size distribution but also from the talc powder distribution. The highlighted phenomenon reveals a detachment not only of simple talc particles (approximately $1 \mu \mathrm{m}$ ) but also mainly of agglomerates (approximately $10 \mu \mathrm{m}$ ).

The graph of Cellets 200 particles with 5\% talc shows that up to a dispersing pressure of 3.9 bar the nPSDs are similar at around $305 \mu \mathrm{m}$. After 3.9 bar pressure 


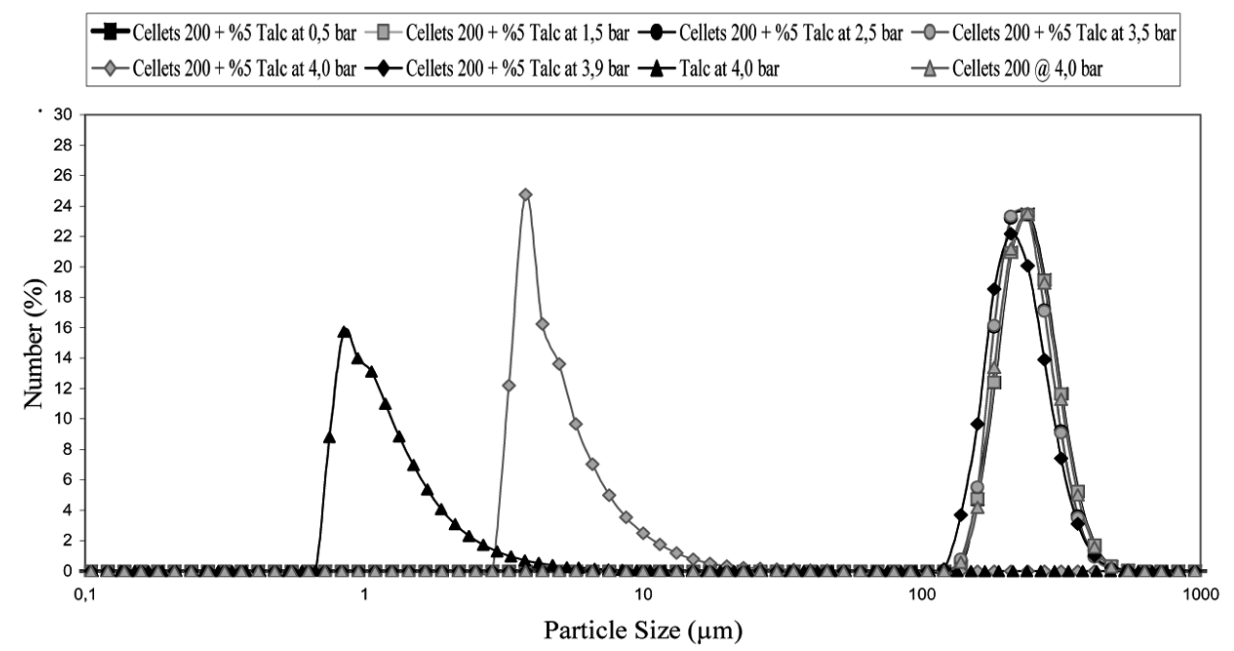

(a)

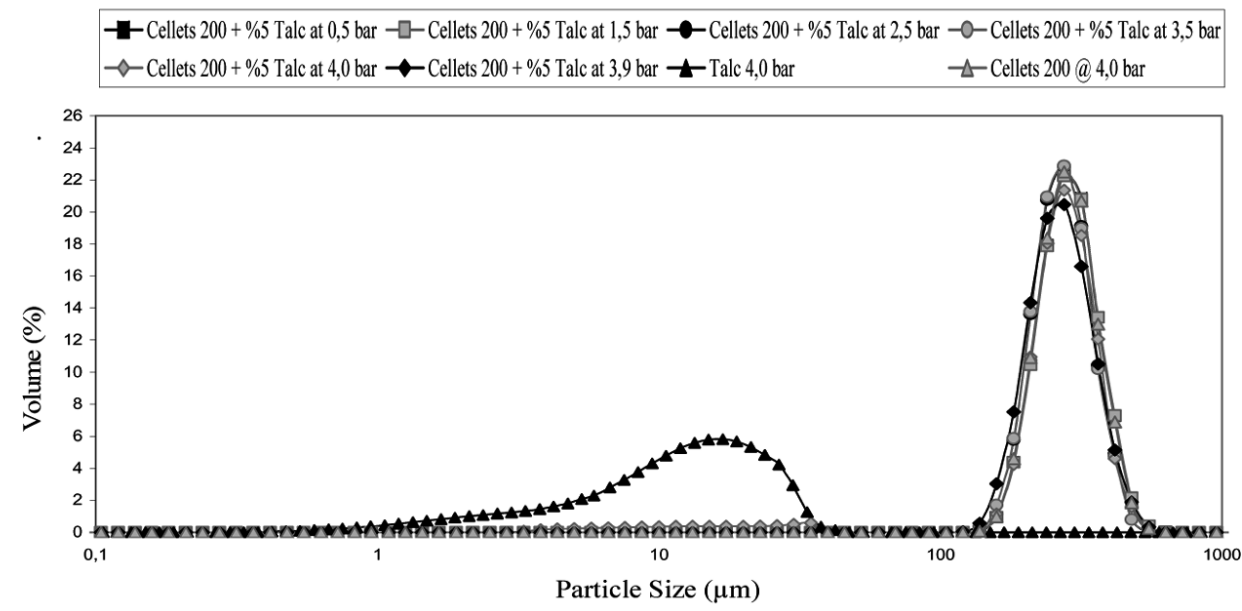

(b)

Figure 5. (a) Evolution of number size distributions with dispersing pressures (Cellets $200+$ $5 \%$ talc in the Hybridizer) and (b) Evolution of volume size distributions with dispersing pressures (Cellets $200+5 \%$ talc in the Hybridizer).

it can be seen that the distribution moves closer to that of the talc. It indicates that the particle detachment for Cellets 200 with $10 \%$ talc powder couple starts at 3.9 bar dispersing pressure. All the data of this characterization method for the various coating processes are given in Table 2 (initial talc: $0.8-0.3 \mu \mathrm{m}$, initial Cellets 90: 82.5-77.1 $\mu \mathrm{m}$, initial Cellets 200: 257.3-251.2 $\mu \mathrm{m})$.

More precisely, the dispersing pressures for particle detachment for both Cellets 90 with $10 \%$ talc and Cellets 200 with $5 \%$ talc powder couples for each dry particle equipment are given in Table 3.

According to the results, it is observed that the coating strength of Cellets 200 with talc particles is stronger than the coating strength of Cellets 90 with talc particles for each type of dry particle equipment. Moreover, if we compare the influence of the equipment on the coating strength, it can be observed that the coating strength of particles that were manipulated in the Hybridizer are stronger than those in the Cyclomix, the Turbula, and the "basic mixing." 
Table 2. Changes in $d(n, 0.5)(\mu \mathrm{m})$ for Cellets with dispersing pressures

\begin{tabular}{|c|c|c|c|c|c|c|c|c|c|}
\hline $\begin{array}{l}\text { Pressure } \\
\text { (bar) }\end{array}$ & $\begin{array}{c}\text { Air } \\
\text { velocity } \\
(\mathrm{m} / \mathrm{s})\end{array}$ & $\begin{array}{c}\text { Cellets } \\
90 \\
\text { (A) }\end{array}$ & $\begin{array}{l}\text { Cellets } \\
90 \\
(\mathrm{~B})\end{array}$ & $\begin{array}{c}\text { Cellets } \\
90 \\
(\mathrm{C})\end{array}$ & $\begin{array}{c}\text { Cellets } \\
90 \\
\text { (D) }\end{array}$ & $\begin{array}{l}\text { Cellets } \\
200 \\
(\mathrm{E})\end{array}$ & $\begin{array}{c}\text { Cellets } \\
200 \\
(\mathrm{~F})\end{array}$ & $\begin{array}{l}\text { Cellets } \\
200 \\
(\mathrm{G})\end{array}$ & $\begin{array}{c}\text { Cellets } \\
200 \\
(\mathrm{H})\end{array}$ \\
\hline 0.5 & 36.0 & 80.1 & 80.7 & 79.8 & 79.5 & 256.4 & 253.8 & 251.1 & 300.9 \\
\hline 1.5 & 71.0 & 80.1 & 80.8 & 1.3 & 4.8 & 256.4 & 243.5 & 249.5 & 4.9 \\
\hline 2.5 & 98.0 & 77.2 & 77.8 & 1.2 & 4.5 & 246.0 & 233.5 & 4.5 & 4.6 \\
\hline 3.5 & 119.0 & 9.7 & 1.8 & 1.2 & 4.5 & 245.7 & 192.0 & 4.4 & 4.5 \\
\hline 4.0 & 128.0 & 6.2 & 1.6 & 1.2 & 1.4 & 4.9 & 4.4 & 4.2 & 4.3 \\
\hline
\end{tabular}

(A) with $10 \%$ talc by Hybridizer; (B) with $10 \%$ talc by Cyclomix; (C) with $10 \%$ talc by Turbula; (D) with $10 \%$ talc by basic mixing; (E) with 5\% talc by Hybridizer; (F), with 5\% talc by Cyclomix; $(\mathrm{G})$ with $5 \%$ talc by Turbula; $(\mathrm{H})$ with $5 \%$ talc by basic mixing.

\section{Van der Waals Forces between Particles}

The objective of this part is to obtain a rough estimation of the effect of host particle size on van der Waals forces between the particles. It is known that the surface roughness may have an important effect on van der Waals forces between the studied particles, but in this preliminary estimation it was not taken into account.

The van der Waals attractive force at solid interfaces that occurs as a result of fluctuating dipoles at the atomic level was integrated by Hamaker (Tabor 1977; Israelachvili 1992; Fatah 2007) to predict the attraction between two macroscopic nondeformable bodies. According to the Hamaker integration, the van der Waals force between two spherical, smooth, and rigid particles denoted 1 and 2 can be derived from Equation (3). $A_{12}$ is the Hamaker constant calculated with Equation (3). $R_{1}$ and $R_{2}$ are the radii of the interacting spheres and $z_{0}$ is the minimum contact distance, classically taken as $0.4 \mathrm{~nm}$. The distance between the particles is considered much smaller than the particle diameters.

$$
\begin{gathered}
F_{v d w}=\frac{A_{12} R_{1} R_{2}}{6\left(R_{1}+R_{2}\right) z_{0}^{2}} \\
A_{12}=\sqrt{A_{11} * A_{22}}
\end{gathered}
$$

For an approximate calculation, the Hamaker constant for Cellets (90 and 200) was taken from the literature as the Hamaker constant of microcrystalline cellulose, as shown in Table 4 (Dreu et al. 2005). At this stage we neglect the effect of surface

Table 3. Detachment dispersing pressures and air velocities for different dry coating equipment

\begin{tabular}{lcc}
\hline Equipment & Cellets 90 with $10 \%$ talc & Cellets 200 with $5 \%$ talc \\
\hline Hybridizer & 3.4 bar; $117 \mathrm{~m} / \mathrm{s}$ & 3.9 bar; $127 \mathrm{~m} / \mathrm{s}$ \\
Cyclomix & 2.9 bar; $106 \mathrm{~m} / \mathrm{s}$ & $3.4 \mathrm{bar} ; 118 \mathrm{~m} / \mathrm{s}$ \\
Turbula & 1.2 bar; $59 \mathrm{~m} / \mathrm{s}$ & 1.8 bar; $82 \mathrm{~m} / \mathrm{s}$ \\
Basic mixing & 0.7 bar; $40 \mathrm{~m} / \mathrm{s}$ & 1.1 bar; $59 \mathrm{~m} / \mathrm{s}$ \\
\hline
\end{tabular}


Table 4. Adhesion estimation between Cellets particles and between Cellets and talc

\begin{tabular}{lcc}
\hline Particle interaction & Hamaker constant $\left(10^{-19} \mathrm{~J}\right)$ & Estimated $F_{v d w}\left(10^{-7} \mathrm{~N}\right)$ \\
\hline Cellets 90 with Cellets 90 & 1.12 & 3 \\
Cellets 90 with talc & 0.97 & 62 \\
Cellets 200 with Cellets 200 & 1.12 & 9 \\
Cellets 200 with talc & 0.97 & 68 \\
Talc with talc & 0.84 & 3 \\
\hline
\end{tabular}

roughness, which may play a very important role (Ramlakhan et al. 2000), but it is supposed to be identical between Cellets 90 and Cellets 200.

The calculated $\mathrm{F}_{v d w}$ values for each powder couple are given in Table 4. The observed general trend is interesting for the coating operation. The adhesion between Cellets-talc $(6.2-6.8 \mu \mathrm{N})$ is greater than that between the host particles $(0.3-$ $0.9 \mu \mathrm{N})$ or between the guest particles $(0.3 \mu \mathrm{N})$. Hence, the dry coating process is helped by the initial adhesion properties of the chosen powders.

It is also observed that the adhesion between Cellets-talc increases with increasing size of the Cellets diameter (expected from Equation (3)), more precisely with the decrease of the guest-to-host size ratio.

Furthermore, the van der Waals approach gives a ratio of the adhesion of $68 / 62=1.1$, which is very close to the ratio of the detachment kinetic energies $127^{2} / 117^{2}=1.2$ in the Hybridizer or $118^{2} / 106^{2}=1.2$ in the Cyclomix. Further experiments should be carried out to confirm the observed trend. Nevertheless, the link between the initial "affinity" and the "mechanical coating strength" is not straightforward. Actually, the process action and the elastic-ductile properties of the materials must also play an important role and are still not taken into account. Nevertheless, in this simplified approach there is a link between the coating strength and the size of the host particle for all the studied processes.

\section{Conclusions}

Dry powder coating is an interesting way for modifying the surface properties of particles. Coating of the host particles by guest particles can be achieved by highenergy impact coating devices and also even by a simple stirring method but not with the same mechanical strength. The Nara Hybridizer (NHS-0) and the Cyclomix were used successfully to coat the two different sizes of Cellets particles as host particles with talc as guest particles with two different weight percentages, $10 \%$ and $5 \%$. The coating strength of the particles depends on the way the host and guest particles are brought into contact and on the physicochemical interactions between them. The van der Waals forces have an important role in particle adhesion and give an idea of the initial adhesion affinity between the powders. To study the influence of the host particle size on the coating strength of the composite particles an experimental method was used. It was observed that the smaller the size ratio of guest and host particles the stronger the coating strength for all the processes used.

There are many factors influencing adhesion: particle size and shape, surface roughness, material hardness and elasticity, and the work of adhesion and surface free energy. Surface roughness is one of the most important characteristic 
influencing adhesion because it is strongly related to the geometry of contact. It will be characterized with atomic force microscopy in a future study.

\section{References}

Dreu, R., J. Sirca , K. Hodi, T. Burjan, \& O. Planinsek. 2005. Physicochemical properties of granulating liquids and their influence on microcrystalline cellulose pellets obtained by extrusion-spheronisation technology. Int. J. Pharm. 291: 99-111.

Fatah, N. 2007. Etude et comparaison des poudres microniques et nanometriques: Approche microscopique pour le calcul des propriétés interparticulaires. Paper presented at Science et Technologie des Poudres, Albi, France, 23-25 May.

Hinrichsen, E. L., J. Feder, \& T. Jossang. 1990. Random packing of disks in two dimensions. Phys. Rev. A 41 (8): 4199-4209.

Israelachvili, J. 1992. Intermolecular and Surface Forces. London: Academic Press.

Mujumdar, A., D. Wei, R. N. Dave, R. Pfeffer, \& C.-Y. Wu. 2004. Improvement of humidity resistance of magnesium powder using dry particle coating. Powder Technol. 140 (1-2): $86-97$.

Ng, B. H., C. C. Kwan, Y. L. Ding, M. Ghadiri, \& X. F. Fan. 2007. Solids motion in a conical frustum-shaped high shear mixer granulator. Chem. Eng. Sci. 62: 756-765.

Ouabbas, Y., J. A. Dodds, A. Chamayou, \& M. Baron. 2007. Particle-particle coating in a Cyclomix impact mixer. Paper presented at 3rd International Granulation Workshop EFCE, Sheffield, UK, 28-29 June.

Pfeffer, R., R. Dave, D. Wei, \& M. Ramlakhan. 2001. Synthesis of engineered particulates with tailored properties using dry particle coating. Powder Technol. 117: 40-67.

Rabinovich, Y .I., J. J. Adler, A. Ata, R. K. Singh, \& B. M. Moudgil. 2000. Adhesion between nanoscale rough surface. I. Role of asperity geometry. J. Colloid Interface Sci. 232: $10-16$.

Ramlakhan, M., C. Wu, S. Watano, R. Dave, \& R. Pfeffer. 2000. Dry particle coating using magnetically assisted impaction coating: Modification of surface properties and optimization of system and operating conditions. Powder Technol. 112: 137-148.

Singh, P., K. Solanky, R. Mudryy, R. Pfeffer, \& R. Dave. 2001. Estimation of coating time in the magnetically assisted impaction coating process. Powder Technol. 121: 159-167.

Tabor, D. 1977. Surface forces and surface interactions. J. Colloid Interface Sci. 58: 2-13.

Vilela, A., A. Chamayou, P. Accart, C. Rolland, M. Baron, \& J. A. Dodds. 2005. The evaluation of the strength of interactions between magnesium stearate and an active pharmaceutical substance coated by mechanical action. In 8th International Symposium on Agglomeration, Bangkok, Thailand, 16-18 March. The Industrial Pharmacists Group, pp. 285-294.

Yang, J., A. Sliva, A. Banerjee, R. Dave, \& R. Pfeffer. 2005. Dry particle coating for improving the flowability of cohesive powders. Powder Technol. 158: 21-33. 